Original Article - Clinical Science

\title{
Real-world assessment of topical glaucoma medication persistence rates based on national pharmaceutical claim data in a defined population
}

\author{
Zhuoting Zhu MD, ${ }^{1}$ Yu Jiang MD, ${ }^{1}$ Wei Wang MD PhD, ${ }^{1}$ Jane Scheetz PhD, ${ }^{2}$ Xianwen \\ Shang $\mathrm{PhD}{ }^{2}$ Lei Zhang $\mathrm{PhD}^{2,3,4,5}$ and Mingguang He MD PhD ${ }^{1,2}$
}

1. State Key Laboratory of Ophthalmology, Zhongshan Ophthalmic Center, Sun Yat-sen University, Guangzhou, China

2. Centre for Eye Research Australia; Ophthalmology, Department of Surgery, University of Melbourne; Royal Victorian Eye and Ear Hospital, Melbourne, Australia

3. Melbourne Sexual Health Centre, Alfred Health, Melbourne, Australia

4. Central Clinical School, Faculty of Medicine, Monash University, Melbourne, Australia

5. Research Centre for Public Health, Tsinghua University, China

Correspondence: Prof Mingguang He, Centre for Eye Research Australia, Ophthalmology, Department of Surgery, University of Melbourne, Royal Victorian Eye and Ear Hospital, Melbourne, Australia mingguang.he@unimelb.edu.au

This is the author manuscript accepted for publication and has undergone full peer review but has not been through the copyediting, typesetting, pagination and proofreading process, which may lead to differences between this version and the Version of Record. Please cite this article as doi: 10.1111/ceo.13524

This article is protected by copyright. All rights reserved. 
AND

A/Prof Lei Zhang, Central Clinical School, Faculty of Medicine, Monash University, Melbourne, Australia

lei.zhang1@monash.edu

Short running title: Persistence of topical glaucoma medication

Received 29 November 2018; accepted 14 April 2019

Funding sources / Financial disclosure: Professor Mingguang He receives support from the University of Melbourne at Research Accelerator Program and the CERA Foundation. The Centre for Eye Research Australia (CERA) receives Operational Infrastructure Support from the Victorian State Government. The specific project is funded by Australia China Research Accelerator Program at CERA. Professor Mingguang $\mathrm{He}$ is also supported by the Fundamental Research Funds of the State Key Laboratory in Ophthalmology, National Natural Science Foundation of China (81420108008). The sponsor or funding organization had no role in the design or conduct of this research.

Conflict of interest: None 


\begin{abstract}
Importance: The rate and determinants of persistence to topical glaucoma medications are important for identifying patients at high-risk of discontinuing medications and designing targeted approaches to improve persistence.
\end{abstract}

Background: To evaluate the rate and determinants of persistence to topical glaucoma medication among middle-aged and older Australian adults.

Design: Population-based cohort study.

Participants: Participants in need of persistent topical glaucoma medications in the 45 and Up Study.

Methods: The 45 and Up Study is a large-scale population-based cohort study. Participants were classified as needing persistent topical glaucoma medications if at least 3 claims with related prescriptions were recorded. Persistence was defined as topical glaucoma medications were filled within 90 days.

Main Outcome Measures: The rates and determinants of medication persistence at 2-year.

Results: A total of 12,899 patients requiring persistent topical glaucoma medications were identified. Among them, 9,019(69.9\%) had persisted with their glaucoma 
medications for at least 2 years. Multiple logistic regression analysis documented significant effects of patient-related factors (gender, socioeconomic status, language spoken at home, lifestyle and comorbidities) and drug related factors (total number and drug class) on the persistence rate. Those most at risk groups of non-persistence were those patients living in remote areas (odds ratio(OR): 0.59,95\% confidence interval(CI):0.37-0.92), having family income over 70000 AUD/year (OR:0.53,95\%CI:0.45-0.62), speaking other languages at home (OR:0.61,95\%CI:0.53-0.68), and using cholinergic classes of medications (OR:0.55,95\%CI:0.38-0.79).

Conclusions and Relevance: Our data has shown a medium level of persistence to topical glaucoma medication among middle-aged and older Australian adults. However, efforts are still needed to improve the rate of persistence.

Keywords: glaucoma topical medication, persistence rate. 


\section{INTRODUCTION}

Glaucoma is the term used for a group of progressive optic neuropathies characterized by loss of retinal ganglion cells and loss of visual field. ${ }^{1}$ It is one of the leading causes of irreversible visual impairment and blindness worldwide ${ }^{2}$ and affects approximately $1.6-3.4 \%$ of the Australian population aged over $50 .^{3}$ As the population continues to age, the number of glaucoma patients worldwide is expected to reach 76.0 million in 2020 and 111.8 million in 2040. ${ }^{4}$ In addition, the global disease burden of blindness and visual impairment due to glaucoma has shown to be significantly associated with a decline in quality of life, ${ }^{5}$ physical functioning, ${ }^{6}$ and mental health. ${ }^{7}$

Despite the fact that the underlying pathophysiology of glaucoma remains unknown, elevated intraocular pressure (IOP) is a well-established risk factor and the only factor that can be modified. ${ }^{1}$ Intra-ocular pressure lowering therapy remains the first line treatment in most glaucoma cases. ${ }^{1}$ Consistent evidence from epidemiological studies and clinical trials has clearly documented the benefits of IOP control in reducing the risk of visual field loss and minimizing the progression of glaucoma. ${ }^{8-15}$ However, similar to other chronic and asymptomatic conditions, many glaucoma patients have struggled to maintain high rates of persistence, with studies showing rates as low as $10 \%$ at 1-year follow-up. ${ }^{16-27}$ Non-persistence can affect patient glaucoma management, leading to great costs and rapid disease progression.

However, previous studies exploring persistence rates of topical glaucoma drugs have been calculated using only hospital-based pharmaceutical claim data, which has the potential to cause selection bias. ${ }^{16-18,24}$ Even though several studies have utilized 
insurance-based claims databases, limited demographic information, lifestyle and comorbidities were collected other than age and sex. ${ }^{19-23}$ To date, only one cohort study in Taiwan and the Glaucoma Adherence and Persistency Study (GAPS) have reported the patient-related determinants of persistence rates for topical glaucoma medications using insurance-based pharmaceutical claims data. ${ }^{25,27}$

Little is known about the rate and determinants for topical glaucoma medication persistence in an Australian population. Only one conference' abstract by Healey et al has documented glaucoma medication persistence, which was $23.7 \%$ at 2 years using a 3 month cessation cut off. ${ }^{28}$ However, like previous studies utilizing claims databases, Healey's analysis could not evaluate the determinants of persistence rates with respect to patient-related factors. A better understanding of patients at high-risk of discontinuing topical glaucoma medication will allow stakeholders design targeted approaches to improve persistence. As such, the aim of this study was to evaluate the rate and determinants of topical glaucoma medication persistence at 2-year follow-up in a large population-based cohort study using national pharmaceutical claim data in Australia.

\section{METHODS}

\subsection{Data source and study design}

The Sax Institute's 45 and Up Study is the largest population-based prospective cohort study in Australia and recruited participants from the general population aged 45 years and above living in New South Wales (NSW). The study methodology has been described in detail elsewhere. ${ }^{29}$ All participants were randomly sampled from the 
Department of Human Services (DHS), formerly Medicare Australia, enrolment database and received a mailed invitation including a study questionnaire, information leaflet and a consent form. The overall response rate was $18 \%$ and nearly $10 \%$ of the entire New South Wales population aged 45 years or older were included in the final sample. A total of 266,896 participants completed a postal questionnaire at baseline (distributed from January 2006 to December 2009) and gave informed consent for follow-up and extraction of their health information from Government databases. The baseline questionnaire data from study participants was linked to the Medicare Benefits Schedule (MBS) and Pharmaceutical Benefits Scheme (PBS) by the Sax Institute using a unique identifier provided by the DHS. Through the MBS, the Australian Government subsidises a list of Medicare services, including professional consultations, pathology and other diagnostic tests. The PBS is Australia's universal pharmaceutical insurance scheme which subsidises essential medications to all residents. ${ }^{30}$ Residents contribute a co-payment for the cost of each subsidized medication and the remaining cost is covered by the PBS. ${ }^{31} \mathrm{~A}$ Concession Card is available for social security beneficiaries who are aged 65 years and older, severely disabled, unemployed or low-income earners. Concession Card holders have a relatively lower subsidy co-payment threshold than general beneficiaries. ${ }^{32}$ Transaction for each subsidized medication dispensed from a community pharmacy is recorded in the PBS. We conducted this analysis by extracting pharmaceutical claims data for participants during the period of 1st January 2006 to 31st December 2016.

Ethical approval for the 45 and Up Study was granted by the University of New South Wales Human Research Ethics Committee (HREC 05035/HREC 10186) and the SEEF 
Study by the University of Sydney Human Research Ethics Committee (reference number: 10-2009/12187).

\subsection{Inclusion and exclusion criteria}

The inclusion and exclusion criteria of the study sample can be found in Figure 1. A participant was identified as requiring persistent topical glaucoma medication if at least 3 claims with related prescriptions were recorded within 1st January 2006 to 31st December 2016. The first glaucoma medication claim data during this period was defined as the index date. Exclusion criteria of the current analysis were as follows: (1) In the absence of detailed medical records, we could not verify whether patients who received laser therapy or glaucoma surgery during the observation period required persistent topical glaucoma medication. Therefore, participants who underwent glaucoma surgery or laser treatment during the study period were excluded; (2) Participants could not be followed up at 2 years after the first glaucoma medication claim date were also excluded.

\subsection{Definition of persistence and non-persistence}

Persistence with topical glaucoma medications was defined as the time intervals of drug refills equal to or less than 90 days based on PBS data. Non-persistence was defined as a gap in two prescription claims exceeding 90 days. A sensitivity analysis was also conducted using treatment gaps based on 60 days or 120 days to explore whether differences existed at different intervals. To verify the robustness of our results, we also assessed persistence as a continuous outcome variable (medication possession ratio, MPR and proportion of days covered, PDC). The MPR was defined as the sum of glaucoma prescription supply days divided by the total days during the 
observation period (two years: 730.5 days). The PDC was calculated by the ratio of days the glaucoma patient was covered by the topical glaucoma medication to the number of days during the observation period (two years: 730.5 days). We assumed that each glaucoma medication prescription may cover 90 days. Sensitivity analysis were also performed for 60 days and 120 days.

\subsection{Covariates}

\subsubsection{Patient-related covariates}

Patient-related covariates were derived from the self-administered questionnaire at baseline. Demographic covariates included age, gender, household income, education level, social economic status (SES), remoteness index, spoken language at home and health insurance cover. Health-related factors included body mass index (BMI), history of diabetes, history of hypertension, drinking and smoking status, and physical activity. Age at index date was calculated as the age at which glaucoma medication was first claimed during the study period. Household income was divided into four groups (Australian dollars): $<\$ 20,000$ per year, $\$ 20,000$ to $\$ 40,000, \$ 40,000$ to $\$ 70,000$ and more than $\$ 70,000$. Education level was categorized into three groups: less than 10 years of education, high school/Trade or apprenticeship and University degree or higher. Participants' SES was determined by Index of Relative Social-Economic Advantage and categorized into quintile, with quintile 1 standing for highest SES and quintile 5 standing for lowest SES. Remoteness index is a standard index of remoteness and can be classified into major cities, inner regional, outer regional, and remote areas. Spoken language at home was categorized into English and other. Health insurance type included private with extras, private with no extras, veteran's card (white or gold), health care concession card and others. Body mass index was 
calculated as self-reported weight in kilograms divided by self-reported height in meters squared $\left(\mathrm{kg} / \mathrm{m}^{2}\right)$ and divided as four groups: underweight $(<18.5)$, normal (18.5-24.9), overweight (25.0-29.9) and obesity ( $\geq 30)$. History of diabetes and hypertension were based on self-report to the question. The approximate number of alcoholic drinks consumed per week was calculated from the baseline questionnaire and categorized as: $<14$ drinks and $\geq 14$ drinks per week. Participants' smoking status was classified into three groups: never, former and current smoker. Physical activity (weekly number of sessions and total time of moderate to vigorous physical activity) was evaluated using the Active Australia Survey which has been found to be a reliable ${ }^{33}$ and valid ${ }^{34}$ measure. Total minutes of moderate to vigorous physical activity (MVPA) per week was calculated by adding minutes of walking, minutes of moderate physical activity, and double the minutes of vigorous physical activity. ${ }^{35}$ Based on current exercise guidelines of moderate intensity physical activity per week, the MVPA was categorized into three groups: $\geq 300,150-300$ and $\leq 150$ minutes per week.

\subsection{Drug-related factors}

During initial analysis, drug-related covariates were based on the last prescription claims of topical glaucoma medications, including the total number and the class of topical glaucoma medication. Sensitivity analysis was repeated using initial prescription claims.

\subsection{Statistical analysis}

Statistical analysis was performed using SAS 9.4. Descriptive statistics were conducted for baseline characteristics of the study participants using the total number of events and persistent status. Categorical variables were expressed as proportions. Univariate 
and multivariate logistic models were used to estimate the odds ratios (ORs) and 95\% confidence intervals (CIs) of baseline characteristics for persistence. Statistical significance was defined as a $P$ value of $<0.05$.

\section{RESULTS}

A total of 19,303 patients were identified as requiring persistent glaucoma medications. Of these patients, 4,882 (25.3\%) had glaucoma-related surgery or laser therapy during the study period and 1,522 (7.88\%) did not reach 2 years after the index day, therefore were excluded from analysis. In total, 12,899 (66.8\%) patients were included in the current analysis (Figure 1). Among the patients who met the inclusion criteria, 9,019 (69.9\%) had persisted with their topical glaucoma medications for at least 2 years, whilst 3,880 (30.1\%) patients discontinued their topical glaucoma medications for an interval of more than 90 days during the 2-year follow-up. Patient-related and drug-related characteristics of included participants by persistent status are presented in Table 1.

The univariate analysis for each patient-related and drug-related variable indicated that patient-related covariates, including age, gender, household income, education level, index of social-economic status and remoteness, language spoken at home, insurance type, diabetes and hypertension status, and drug-related covariates, including total number of medications, beta-blocker, carbonic anhydrase inhibitor, prostaglandin analogues and FDC classes of medications were significantly associated with persistence rates. These findings are shown in Table 2. 
Multivariate adjusted results are summarised in Table 2. After controlling for all covariates, females had a significantly higher rate of persistence than males $(O R=1.19$, 95\% CI: 1.09-1.29). Patients with lower household income and those from a disadvantaged socioeconomic background ( $5^{\text {th }}$ quintile of SES) were less likely to discontinue their topical glaucoma medication treatments than those who had a household income more than 40000 AUD/y and patients with higher SES (all P < 0.05). Relative to patients living in urban areas, those from remote areas were more likely to discontinue their glaucoma treatments ( $\mathrm{OR}=0.59,95 \% \mathrm{CI}$ : 0.37-0.92), while those living in the inner regional areas tended to have better persistence with their topical glaucoma medications at 2-year follow-up ( $\mathrm{OR}=1.10,95 \% \mathrm{CI}: 1.00-1.21)$. Patients who spoke English at home had a higher rate of persistence than those who spoke other languages at home ( $\mathrm{OR}=1.65,95 \% \mathrm{CI}: 1.46-1.87)$. Health insurance type, diabetes and hypertension status, physical activity, and smoking habit were also associated with the patient's persistence (all $P<0.05$ ).

In terms of drug-related variables, those prescribed a greater number of glaucoma medications had an increased chance of being more persistent than those who were prescribed one topical glaucoma medication (two medications: OR: $2.08,95 \% \mathrm{CI}$ : 1.71-2.53; more than two medications: OR: $3.23,95 \%$ CI: $1.71-6.09)$. Those who used adrenergic, beta-blocker, or cholinergic classes of medication at the last prescription tended to discontinue treatment compared to those not using the corresponding class of medication (all $P<0.05$ ).

The persistence rate was $44.3 \%$ and $80.6 \%$ at the 2 -year follow-up with the criteria for non-persistence as a gap of more than 60 days and more than 120 days, 
respectively. Multivariate analysis based on these definitions led to similar findings. Repeated analysis based on the first prescription claims data also resulted in similar findings (Supplement table 1). We also observed results comparable to those of the main analysis when persistence was assessed as a continuous variable (MPR or PDC) in the models (Supplement table 2).

\section{DISCUSSION}

In the current study, we found a medium level of persistence (69.9\% at 2-year) for topical glaucoma medication in a large Australian population-based cohort study. This study further documented significant effects of patient-related factors (gender, socioeconomic status, language spoken at home, lifestyles and comorbidities) and drug related factors (total number and classes of drugs) on the persistence rates. The most at risk groups for non-persistence were patients living in remote areas, having family income more than 70,000 AUD/y, speaking language other than English at home, and using the cholinergic class of medications.

The medium rate of persistence (69.9\% at 2-year) among glaucoma patients in our study was comparable to findings reported from European data (69\%-84\% follow-up at 2 to 3 years). ${ }^{16-18}$ Whilst it was higher than those from United States Medicare and Asian which showed consistently lower persistence rates across different classes of agents (11.5-64\%) with a mean interval of therapy up to 3 years..$^{21,23-25,36-38}$ In comparison to a previous report by Healey et al that found relatively low persistence rates ( $23.7 \%$ at 2 -year using the 3 month cessation ruling $)^{28}$ we reported that more than two thirds of patients in need of persistent topical medications had continued to 
use their drugs at 2-year follow-up. Interestingly, Healey's report was based on claims data before the 2010 Australian National Health and Medical Research Council Guidelines for the Screening, Prognosis, Diagnosis, Management and Prevention of Glaucoma recommendations were released. These guidelines recommended once-daily topical prostaglandin analogues as first line treatment. The higher persistence rates in our study may potentially be explained by the fact that a high proportion of patients in our study were first prescribed medication following the release of these guidelines and the greater tolerability and efficiency associated with the use of prostaglandin analogues. ${ }^{39}$ Despite of the difference in study period, this disparity of persistence rate between our study and Healey's report may also be related to the differences in population characteristics (e.g., age distribution, socioeconomic status, severity of glaucoma), study methodology (logistic regression model versus Cox proportional regression model), definition of patients in need of persistent glaucoma medications (at least three versus one glaucoma-related medication claims).

Speaking English at home was found to have a significant impact on persistence to topical glaucoma medication in comparison to those who spoke other languages at home. This finding might be due to the difficulty in communicating with doctors and cultural barriers. ${ }^{40,41}$ Interestingly, we found that patients from more disadvantaged socioeconomic backgrounds and those living in inner regional areas were associated with higher glaucoma medication persistence, which was inconsistent with previous studies. ${ }^{25,42-44}$ Previous studies have reported that glaucoma patients who are from a low socioeconomic background were less likely to be screened and treated for glaucoma ${ }^{45}$ and therefore, were more likely to present with advanced disease when 
they were prescribed with topical glaucoma medications ${ }^{46}$ The fear of blindness might improve those patients' persistence. We found that female glaucoma patients were more persistent with their treatment than males, which is supported by previous studies. ${ }^{47,48} \mathrm{~A}$ large number of studies have confirmed gender differences in health care behaviors, ${ }^{49}$ which may be one of the reasons why female patients tended to have better topical glaucoma medication persistence. In the present analysis, patients with hypertension were more persistent with their treatment while diabetic patients were less likely to continue their topical glaucoma medication treatment. Evidence suggests that both untreated hypertension and over-treated hypertension with resultant low blood pressure (BP), particularly with low night time BP, are closely associated with glaucoma progression. ${ }^{50}$ This may explain the greater persistence among patients with hypertension. However, the relationship between diabetes and glaucoma is still conflicting. ${ }^{51}$ Nevertheless, growing evidence indicates that metformin, a first-line anti-diabetic agent, is associated with a reduction in the risk of developing glaucoma. ${ }^{51}$ Furthermore, a recent cohort study found that primary open angle glaucoma (POAG) patients with type 2 diabetes mellitus (DM), particularly with treated type 2 DM, had significantly slower rates of retinal nerve fiber layer thinning compared to those without DM..$^{52}$ Over-expression of vascular endothelial growth factor in the retina of diabetics ${ }^{53}$ or protective effects of metformin on mitochondrial function and retinal ganglion cells $s^{54,55}$ may be the underlying mechanism for the protective effect against glaucomatous damage. All these findings may imply that the relatively slower progression of glaucoma may be a potential explanation for the poorer persistence among diabetic patients. The better persistence among non-smoking and physically active patients may be the result of a healthier lifestyle or a better awareness and knowledge of glaucoma. The type of health insurance also 
correlated with persistence rate. The relatively lower subsidy co-payment threshold than general beneficiaries may explain the better persistence with topical glaucoma medication among concession card holders. One potential reason why patients who hold a veteran's card were more likely to discontinue their glaucoma treatment may be due to their potential access to pharmaceuticals under a separate funding scheme.

With respect to drug-related factors, the greater number of prescribed glaucoma medications was a significant predictor for better persistence rates. The effects of multiple medications on the persistence were still conflicting. ${ }^{25,43,44}$ The inconvenience and tolerability of increased number of agents have been reported to negatively affect adherence. ${ }^{56}$ However, the greater number of topical glaucoma medications may indicate the disease severity and more difficulty of controlling IOP, thus increasing the fear of blindness and improving persistence rates. In terms of the class of medication, we found a significant association between the use of prostaglandin analogues and better persistence rates in the unadjusted model, which was supported by findings from previous studies. ${ }^{22,25,36,38}$ However, a significant association between the use of prostaglandin analogues and persistence was not seen after multiple adjustments, which may be due to the large proportion of patients using prostaglandin in the current analysis (59\%). In contrast, the use of adrenergic, beta-blocker, and cholinergic classes of medications were significant barriers to persistence. Possible reasons for these patients discontinuing therapy might include side effects, inconvenience (more than once-a-day administration) and low efficiency of these classes of drugs. 
Given the persistence to topical IOP-lowering medication is critical for delaying progression, subsequent vision loss and improving quality of life, our findings may have several practical implications. First, our findings provide evidence on the determinants of poor persistence with respect to patient-related and drug-related factors. This may identify patients at high-risk of discontinuing topical glaucoma medication. Second, health promotion-based efforts tailored to individual patient's specific barriers and health lifestyles will be effective toward promoting long-term adherence and resulting in better health outcomes among glaucoma patients. Such as, provision of well-trained translator services may eliminate language barriers for non-English speaking patients.

This study had a number of strengths. First, the large number of patients in need of topical glaucoma medication provides strong statistical power. Second, the claims data better reflects real-world situation than those from controlled clinical trials. Third, our study provides a broad array of covariates to explore determinants of persistence rates of topical glaucoma medication. However, several potential limitations should also be considered. First, the overall response rate of the baseline questionnaire was only $18 \%$, therefore, persistence rates with topical glaucoma medication in the present analysis can not be extrapolated to the entire population in NSW or in Australia. Nevertheless, the relationship between covariates and persistence of topical glaucoma medication is still reasonable and unaffected. Second, participants in the 45 and Up study tend to be healthier than the overall population, ${ }^{57}$ which might overestimate the persistence rate. Third, as our study was only based on the PBS claims data, we were unable to access data on prescriptions filled in the public hospitals and exclude patients who died or left PBS system during the study period, 
which might underestimate persistence rates. Fourth, patient characteristics were collected on a single occasion using self-report. During the follow-up period, participants behavior may change, which can have a direct impact on outcomes. Last but not least, patient medical records were not able to be reviewed. This means that accurate data on disease diagnosis and severity is absent. The definition of need for persistent topical glaucoma medication used may be seen as a potential limitation. The minimum of at least 3 claims related to topical glaucoma medication may have included patients requiring only short-term therapy (e.g., IOP spikes after cataract surgery, trauma), leading an underestimation of persistence.

In summary, this large-scale population-based cohort study showed medium rates of persistence to glaucoma medical therapy. Patient-related factors, including socioeconomic status, languages spoken at home and number and class of medications were predictors of better persistence at 2-years. Efforts are still needed for improving adherence, particularly among patients living in remote areas and speaking other languages other than English at home.

\section{Acknowledgement}

This research was completed using data collected from the 45 and Up Study (www.saxinstitute.org.au). The 45 and Up Study is managed by the Sax Institute in collaboration with major partner Cancer Council NSW; and partners: the National Heart Foundation of Australia (NSW Division); NSW Ministry of Health; NSW Government Family \& Community Services -Ageing, Carers and the Disability Council NSW; and the Australian Red Cross Blood Service. We thank the many thousands of people participating in the 45 and Up Study. 


\section{REFERENCES}

1. Weinreb RN, Aung T, Medeiros FA. The pathophysiology and treatment of glaucoma: a review. Jama 2014; 311: 1901-11.

2. Thylefors B, Negrel AD. The global impact of glaucoma. Bulletin of the World Health Organization 1994; 72: 323-6.

3. Keel S, Xie J, Foreman J, Lee PY, Alwan M, Fahy ET, van Wijngaarden P, Fan Gaskin JC, Ang GS, Crowston JG, Taylor HR, Dirani M. Prevalence of glaucoma in the Australian National Eye Health Survey. The British journal of ophthalmology 2018.

4. Tham YC, Li X, Wong TY, Quigley HA, Aung T, Cheng CY. Global prevalence of glaucoma and projections of glaucoma burden through 2040: a systematic review and meta-analysis. Ophthalmology 2014; 121: 2081-90.

5. Quaranta L, Riva I, Gerardi C, Oddone F, Floriano I, Konstas AG. Quality of Life in Glaucoma: A Review of the Literature. Advances in therapy 2016; 33: 959-81.

6. Yip JL, Broadway DC, Luben R, Garway-Heath DF, Hayat S, Dalzell N, Lee PS, Bhaniani A, Wareham NJ, Khaw KT, Foster PJ. Physical activity and ocular perfusion pressure: the EPIC-Norfolk eye study. Invest Ophthalmol Vis Sci 2011; 52: 8186-92.

7. Chan EW, Chiang PP, Liao J, Rees G, Wong TY, Lam JS, Aung T, Lamoureux E. Glaucoma and associated visual acuity and field loss significantly affect glaucoma-specific psychosocial functioning. Ophthalmology 2015; 122: 494-501. 
8. Chauhan BC, Mikelberg FS, Balaszi AG, LeBlanc RP, Lesk MR, Trope GE, Canadian Glaucoma Study G. Canadian Glaucoma Study: 2. risk factors for the progression of open-angle glaucoma. Arch Ophthalmo/2008; 126: 1030-6.

9. Boland MV, Ervin AM, Friedman DS, Jampel HD, Hawkins BS, Vollenweider D, Chelladurai Y, Ward D, Suarez-Cuervo C, Robinson KA. Comparative effectiveness of treatments for open-angle glaucoma: a systematic review for the U.S. Preventive Services Task Force. Ann Intern Med 2013; 158: 271-9.

10. Miglior S, Zeyen T, Pfeiffer N, Cunha-Vaz J, Torri V, Adamsons I, European Glaucoma Prevention Study G. Results of the European Glaucoma Prevention Study. Ophthalmology 2005; 112: 366-75.

11. Kass MA, Heuer DK, Higginbotham EJ, Johnson CA, Keltner JL, Miller JP, Parrish RK, 2nd, Wilson MR, Gordon MO. The Ocular Hypertension Treatment Study: a randomized trial determines that topical ocular hypotensive medication delays or prevents the onset of primary open-angle glaucoma. Arch Ophthalmo/2002; 120: 701-13; discussion 829-30.

12. Heijl A, Leske MC, Bengtsson B, Hyman L, Bengtsson B, Hussein M, Early Manifest Glaucoma Trial G. Reduction of intraocular pressure and glaucoma progression: results from the Early Manifest Glaucoma Trial. Arch Ophthalmol 2002; 120: 1268-79.

13. The effectiveness of intraocular pressure reduction in the treatment of normal-tension glaucoma. Collaborative Normal-Tension Glaucoma Study Group. Am J Ophthalmol 1998; 126: 498-505.

14. The Advanced Glaucoma Intervention Study (AGIS): 7. The relationship between control of intraocular pressure and visual field deterioration.The AGIS Investigators. Am J Ophthalmo/ 2000; 130: 429-40. 
15. Leske MC, Heijl A, Hussein M, Bengtsson B, Hyman L, Komaroff E, Early Manifest Glaucoma Trial G. Factors for glaucoma progression and the effect of treatment: the early manifest glaucoma trial. Arch Ophthalmo/ 2003; 121: 48-56.

16. Diestelhorst M, Schaefer $\mathrm{CP}$, Beusterien KM, Plante KM, Fain JM, Mozaffari E, Dhawan R. Persistency and clinical outcomes associated with latanoprost and beta-blocker monotherapy: evidence from a European retrospective cohort study. Eur J Ophthalmo/ 2003; 13 Suppl 4: S21-9.

17. Bernard LM, Althin R, Dhawan R, Grima DT, Lam A, Aballea S. Clinical and economic impacts of latanoprost $0.005 \%$ in first-line treatment of open-angle glaucoma and ocular hypertension in France. Eur J Ophthalmo/2003; 13 Suppl 4: S30-43.

18. Rouland JF, Le Pen C, Ophthalmologists of the Glaucoma S. Naturalistic, prospective study of glaucoma and ocular hypertension treatment in France: strategies, clinical outcomes, and costs at 1 year. Eur J Ophthalmo/2003; 13 Suppl 4: S5-20.

19. Freedman RB, Jones SK, Lin A, Robin AL, Muir KW. Influence of parental health literacy and dosing responsibility on pediatric glaucoma medication adherence. Arch Ophthalmo/ 2012; 130: 306-11.

20. Lee PP, Walt JG, Chiang TH, Guckian A, Keener J. A gap analysis approach to assess patient persistence with glaucoma medication. Am J Ophthalmol 2007; 144: $520-4$.

21. Nordstrom BL, Friedman DS, Mozaffari E, Quigley HA, Walker AM. Persistence and adherence with topical glaucoma therapy. Am J Ophthalmo/2005; 140: 598-606. 
22. Schwartz GF, Reardon G, Mozaffari E. Persistency with latanoprost or timolol in primary open-angle glaucoma suspects. Am J Ophthalmo/ 2004; 137: S13-6.

23. Spooner JJ, Bullano MF, Ikeda LI, Cockerham TR, Waugh WJ, Johnson T, Mozaffari E. Rates of discontinuation and change of glaucoma therapy in a managed care setting. Am J Manag Care 2002; 8: S262-70.

24. Quek DT, Ong GT, Perera SA, Lamoureux EL, Aung T. Persistence of patients receiving topical glaucoma monotherapy in an Asian population. Arch Ophthalmol2011; 129: 643-8.

25. Hwang DK, Liu CJ, Pu CY, Chou YJ, Chou P. Persistence of topical glaucoma medication: a nationwide population-based cohort study in Taiwan. JAMA Ophthalmo/2014; 132: 1446-52.

26. Schwartz GF, Quigley HA. Adherence and persistence with glaucoma therapy. Surv Ophthalmo/2008; 53 Suppl1: S57-68.

27. Friedman DS, Hahn SR, Gelb L, Tan J, Shah SN, Kim EE, Zimmerman TJ, Quigley HA. Doctor-patient communication, health-related beliefs, and adherence in glaucoma results from the Glaucoma Adherence and Persistency Study. Ophthalmology 2008; 115: 1320-7, 7 e1-3.

28. P. Healey IG, K. Subramaniam, A. Kemp. Loss to follow-up may be reason for poor glaucoma medication adherence. Poster. World Glaucoma Congress Paris 2011.

29. Up Study C, Banks E, Redman S, Jorm L, Armstrong B, Bauman A, Beard J, Beral V, Byles J, Corbett S, Cumming R, Harris M, Sitas F, Smith W, Taylor L, Wutzke S, Lujic S. Cohort profile: the 45 and up study. Int J Epidemio/ 2008; 37: 941-7. 
30. Australian Government-Department of Health. Pharmaceutical Benefits Scheme (PBS)-About the PBS 2019. Available from:

http://www.pbs.gov.au/pbs/about-the-pbs. Accessed January 16, 2019.

31. Hynd A, Roughead EE, Preen DB, Glover J, Bulsara M, Semmens J. The impact of co-payment increases on dispensings of government-subsidised medicines in Australia. Pharmacoepidemiol Drug Saf 2008; 17: 1091-9.

32. Australian Government-Department of Health. Fees, Patient Contributions and Safety Net Thresholds 2019. Available from:

http://www.pbs.gov.au/info/healthpro/explanatory-notes/front/fee. Accessed January 16, 2019.

33. Brown WJ, Trost SG, Bauman A, Mummery K, Owen N. Test-retest reliability of four physical activity measures used in population surveys. Journal of science and medicine in sport 2004; 7: 205-15.

34. Heesch KC, Hill RL, van Uffelen JG, Brown WJ. Are Active Australia physical activity questions valid for older adults? Journal of science and medicine in sport 2011; 14: 233-7.

35. Australian Institute of Health and Welfare. The Active Australia survey: a guide and manual for implementation, analysis and reporting. Canberra, Australia, Australian Institute of Health and Welfare, 2003.

36. Reardon G, Schwartz GF, Mozaffari E. Patient persistency with topical ocular hypotensive therapy in a managed care population. Am J Ophthalmo/ 2004;

137: S3-12.

37. Wilensky J, Fiscella RG, Carlson AM, Morris LS, Walt J. Measurement of persistence and adherence to regimens of IOP-lowering glaucoma medications using pharmacy claims data. Am J Ophthalmo/2006; 141: S28-33. 
38. Dasgupta S, Oates V, Bookhart BK, Vaziri B, Schwartz GF, Mozaffari E. Population-based persistency rates for topical glaucoma medications measured with pharmacy claims data. Am J Manag Care 2002; 8: S255-61.

39. King A, Azuara-Blanco A, Tuulonen A. Glaucoma. Bmj 2013; 346: f3518.

40. Wisnivesky JP, Krauskopf K, Wolf MS, Wilson EA, Sofianou A, Martynenko M, Halm EA, Leventhal $H$, Federman AD. The association between language proficiency and outcomes of elderly patients with asthma. Ann Allergy Asthma Immuno/ 2012; 109: 179-84.

41. Warren JR, Falster MO, Fox D, Jorm L. Factors influencing adherence in long-term use of statins. Pharmacoepidemiol Drug Saf2013; 22: 1298-307.

42. Dreer LE, Girkin C, Mansberger SL. Determinants of medication adherence to topical glaucoma therapy. J Glaucoma 2012; 21: 234-40.

43. Budenz DL. A clinician's guide to the assessment and management of nonadherence in glaucoma. Ophthalmology 2009; 116: S43-7.

44. Olthoff CM, Schouten JS, van de Borne BW, Webers CA. Noncompliance with ocular hypotensive treatment in patients with glaucoma or ocular hypertension an evidence-based review. Ophthalmology 2005; 112: 953-61.

45. Owen CG, Carey IM, De Wilde S, Whincup PH, Wormald R, Cook DG. The epidemiology of medical treatment for glaucoma and ocular hypertension in the United Kingdom: 1994 to 2003. The British journal of ophthalmology 2006; 90: 861-8.

46. Fraser S, Bunce C, Wormald R, Brunner E. Deprivation and late presentation of glaucoma: case-control study. Bmj 2001; 322: 639-43.

47. Konstas AG, Maskaleris G, Gratsonidis S, Sardelli C. Compliance and viewpoint of glaucoma patients in Greece. Eye (Lond) 2000; 14 Pt 5: 752-6. 
48. Kim CY, Park KH, Ahn J, Ahn MD, Cha SC, Kim HS, Kim JM, Kim MJ, Kim TW, Kim YY, Lee JW, Park SW, Sohn YH, Sung KR, Yoo C, Cha J, Kim YJ. Treatment patterns and medication adherence of patients with glaucoma in South Korea. The British journal of ophthalmology 2017; 101: 801-7.

49. Thompson AE, Anisimowicz Y, Miedema B, Hogg W, Wodchis WP, Aubrey-Bassler K. The influence of gender and other patient characteristics on health care-seeking behaviour: a QUALICOPC study. BMC Fam Pract 2016; 17: 38.

50. Levine RM, Yang A, Brahma V, Martone JF. Management of Blood Pressure in Patients with Glaucoma. Curr Cardiol Rep 2017; 19: 109.

51. Lin HC, Stein JD, Nan B, Childers D, Newman-Casey PA, Thompson DA, Richards JE. Association of Geroprotective Effects of Metformin and Risk of Open-Angle Glaucoma in Persons With Diabetes Mellitus. JAMA Ophthalmol 2015; 133: 915-23.

52. Hou H, Shoji T, Zangwill LM, Moghimi S, Saunders L, Hasenstab K, Ghahari E, Manalastas PIC, Akagi T, Christopher M, Penteado RC, Weinreb RN.

Progression of Primary Open-Angle Glaucoma in Diabetic and Nondiabetic Patients. Am J Ophthalmo/2018; 189: 1-9.

53. Song BJ, Aiello LP, Pasquale LR. Presence and Risk Factors for Glaucoma in Patients with Diabetes. Curr Diab Rep 2016; 16: 124.

54. Kim YS, Kim M, Choi MY, Lee DH, Roh GS, Kim HJ, Kang SS, Cho GJ, Kim SJ, Yoo JM, Choi WS. Metformin protects against retinal cell death in diabetic mice. Biochem Biophys Res Commun 2017; 492: 397-403. 
55. Abdelgadir E, Ali R, Rashid F, Bashier A. Effect of Metformin on Different Non-Diabetes Related Conditions, a Special Focus on Malignant Conditions: Review of Literature. J Clin Med Res 2017; 9: 388-95.

56. Robin AL, Novack GD, Covert DW, Crockett RS, Marcic TS. Adherence in glaucoma: objective measurements of once-daily and adjunctive medication use. Am J Ophthalmo/ 2007; 144: 533-40.

57. Mealing NM, Banks E, Jorm LR, Steel DG, Clements MS, Rogers KD. Investigation of relative risk estimates from studies of the same population with contrasting response rates and designs. BMC medical research methodology 2010; 10: 26.

\section{FIGURE LEGEND}

Figure 1: Schematic showing study participants included for the present analysis from the 45 and Up Study. A total of 19,303 patients were identified in need of persistent glaucoma medical treatment. Of these patients, 4,882 cases (25.3\%) had glaucoma-related surgery during the study period and 1,522 cases $(7.88 \%)$ reach the 
study end date (Dec 31th 2016) within 2 years after the index day, thus leading to $12,899(66.8 \%)$ patients in the current analysis.

* Index day is defined as the date when patient's condition was first treated with glaucoma medication during the study period. 


\section{TABLES}

Table 1: Total patient-related and drug-related covariates of participants and persistence status

\begin{tabular}{|c|c|c|c|}
\hline Characteristics & Overall & $\begin{array}{c}\text { Subjects with } \\
\text { Persistence }\end{array}$ & $\begin{array}{c}\text { Subjects with } \\
\text { Non-Persistence }\end{array}$ \\
\hline Overall & 12,899 & 9,019 & 3,880 \\
\hline \multicolumn{4}{|l|}{ Demographic } \\
\hline \multicolumn{4}{|l|}{ Age at index date, yrs } \\
\hline $45-49$ & $181(1.4)$ & $112(1.2)$ & $69(1.8)$ \\
\hline $50-54$ & $422(3.3)$ & $250(2.8)$ & $172(4.4)$ \\
\hline $55-59$ & $803(6.2)$ & $512(5.7)$ & $291(7.5)$ \\
\hline $60-65$ & $1,407(10.9)$ & $938(10.4)$ & $469(12.1)$ \\
\hline$>65$ & $10,086(78.2)$ & 7,207 (79.9) & $2,879(74.2)$ \\
\hline Female gender & $6,390(49.5)$ & $4,627(51.3)$ & $1,763(45.4)$ \\
\hline \multicolumn{4}{|l|}{ Household income (AUD/y) } \\
\hline$<20000$ & $3,799(29.5)$ & $2,823(31.3)$ & $976(25.2)$ \\
\hline $20000-40000$ & $2,647(20.5)$ & $1,935(21.5)$ & $712(18.4)$ \\
\hline $40000-70000$ & $1,599(12.4)$ & $1,048(11.6)$ & $551(14.2)$ \\
\hline$>70000$ & $1,369(10.6)$ & $755(8.4)$ & $614(15.8)$ \\
\hline \multicolumn{4}{|l|}{ Highest education } \\
\hline No qualification & $2,108(16.3)$ & $1,527(16.9)$ & $581(15.0)$ \\
\hline Certificate/diploma/trade & $8,220(63.7)$ & $5,866(65.0)$ & $2,354(60.7)$ \\
\hline University & $2,231(17.3)$ & $1,397(15.5)$ & $834(21.5)$ \\
\hline \multicolumn{4}{|l|}{ Quintile of SES } \\
\hline $1^{\text {st }}$ Quintile & $3,095(24.0)$ & $2,236(24.8)$ & $859(22.1)$ \\
\hline $2^{\text {nd }}$ Quintile & $2,631(20.4)$ & $1,926(21.4)$ & 705 (18.2) \\
\hline $3^{\text {rd }}$ Quintile & 2,286 (17.7) & 1,613 (17.9) & $673(17.3)$ \\
\hline $4^{\text {th }}$ Quintile & $1,969(15.3)$ & $1,341(14.9)$ & $628(16.2)$ \\
\hline $5^{\text {th }}$ Quintile & $2,635(20.4)$ & 1,705 (18.9) & $930(24.0)$ \\
\hline \multicolumn{4}{|l|}{ Remoteness } \\
\hline Major Cities & $7,292(56.5)$ & $4,966(55.1)$ & $2,326(59.9)$ \\
\hline Inner Regional & $4,192(32.5)$ & 3,053 (33.9) & $1,139(29.4)$ \\
\hline Outer Regional & $1,155(9.0)$ & $837(9.3)$ & $318(8.2)$ \\
\hline
\end{tabular}

This article is protected by copyright. All rights reserved. 


\begin{tabular}{|c|c|c|c|}
\hline Remote or very Remote & $83(0.6)$ & $49(0.5)$ & $34(0.9)$ \\
\hline $\begin{array}{l}\text { English language speaking at } \\
\text { home }\end{array}$ & $11,624(90.1)$ & $8,263(91.6)$ & $3,361(86.6)$ \\
\hline \multicolumn{4}{|l|}{ Health insurance type } \\
\hline Private with extras & $4,141(32.1)$ & 2,701 (29.9) & $1,440(37.1)$ \\
\hline Private no extras & $1,356(10.5)$ & $943(10.5)$ & $413(10.6)$ \\
\hline Veterans card & $187(1.4)$ & $120(1.3)$ & $67(1.7)$ \\
\hline Concession card & $5,528(42.9)$ & $4,081(45.2)$ & $1,447(37.3)$ \\
\hline None of above & $1,356(10.5)$ & $935(10.4)$ & $421(10.9)$ \\
\hline \multicolumn{4}{|l|}{ Clinical } \\
\hline \multicolumn{4}{|l|}{$\mathrm{BMI}, \mathrm{kg} / \mathrm{m}^{2}$} \\
\hline Underweight & $218(1.7)$ & $149(1.7)$ & $69(1.8)$ \\
\hline Normal & $4,488(34.8)$ & $3,250(36.0)$ & $1,238(31.9)$ \\
\hline Overweight & $4,686(36.3)$ & $3,223(35.7)$ & $1,463(37.7)$ \\
\hline Obesity & 2,523 (19.6) & $1,704(18.9)$ & $819(21.1)$ \\
\hline Diabetes & $1,949(15.1)$ & $1,303(14.4)$ & $646(16.6)$ \\
\hline High blood pressure & $6,020(46.7)$ & $4,323(47.9)$ & $1,697(43.7)$ \\
\hline \multicolumn{4}{|l|}{ Lifestyle } \\
\hline \multicolumn{4}{|l|}{ Smoker } \\
\hline No & $7,573(58.7)$ & $5,321(59.0)$ & $2,252(58.0)$ \\
\hline Past smoker & $4,799(37.2)$ & $3,358(37.2)$ & $1,441(37.1)$ \\
\hline Current smoker & $521(4.0)$ & $337(3.7)$ & $184(4.7)$ \\
\hline $\begin{array}{l}\text { Alcohol consumption per week } \\
\text { ( } \geq 14 \text { drinks) }\end{array}$ & $2,284(17.7)$ & $1,577(17.5)$ & $707(18.2)$ \\
\hline \multicolumn{4}{|l|}{ PA (session/week) } \\
\hline$<5$ & $2,812(21.8)$ & $1,953(21.7)$ & $859(22.1)$ \\
\hline$\geq 5-9$ & $3,270(25.4)$ & $2,326(25.8)$ & $944(24.3)$ \\
\hline$\geq 9$ & $2,787(21.6)$ & $1,949(21.6)$ & $838(21.6)$ \\
\hline \multicolumn{4}{|l|}{ MVAP } \\
\hline$\geq 300 \mathrm{~min}$ & $5,442(42.2)$ & $3,803(42.2)$ & $1,639(42.2)$ \\
\hline $150-300 \mathrm{~min}$ & $1,565(12.1)$ & $1,061(11.8)$ & $504(13.0)$ \\
\hline$\leq 150 \min$ & $5,050(39.2)$ & $3,572(39.6)$ & $1,478(38.1)$ \\
\hline \multicolumn{4}{|l|}{ Medication-related factors } \\
\hline \multicolumn{4}{|l|}{ No. of medications } \\
\hline 1 & $12,059(93.5)$ & $8,334(92.4)$ & $3,725(96.0)$ \\
\hline 2 & 759 (5.9) & $616(6.8)$ & $143(3.7)$ \\
\hline
\end{tabular}

This article is protected by copyright. All rights reserved. 


\begin{tabular}{lccc}
\hline$\geq 3$ & $81(0.6)$ & $69(0.8)$ & $12(0.3)$ \\
Use of FDC & $2,490(19.3)$ & $1,789(19.8)$ & $701(18.1)$ \\
Use of beta-blocker & $2,109(16.4)$ & $1,427(15.8)$ & $682(17.6)$ \\
Use of adrenergic & $905(7.0)$ & $634(7.0)$ & $271(7.0)$ \\
Use of cholinergic & $138(1.1)$ & $87(1.0)$ & $51(1.3)$ \\
Use of CAI & $575(4.5)$ & $441(4.9)$ & $134(3.5)$ \\
Use of prostaglandin analogues & $7,606(59.0)$ & $5,398(59.9)$ & $2,208(56.9)$ \\
\hline
\end{tabular}

Values are all listed as $\mathrm{n}(\%)$. Abbreviation: SES = social economic status; PA = physical activity; MVPA = moderate to vigorous physical activity; $F D C=$ fixed combination; CAI = carbonic anhydrase inhibitor 
Table 2: Unadjusted and multiple-adjusted logistic regression analysis of determinants for persistence

\begin{tabular}{|c|c|c|c|c|c|}
\hline \multirow[t]{2}{*}{ Characteristics } & \multirow{2}{*}{$\begin{array}{l}\text { Persistence } \\
\text { Event/N }\end{array}$} & \multicolumn{2}{|c|}{ Unadjusted } & \multicolumn{2}{|c|}{ Multiple adjusted $^{+}$} \\
\hline & & OR (95\% CI) & $P$ value & OR (95\% CI) & $P$ value \\
\hline \multicolumn{6}{|l|}{ Demographic } \\
\hline 45-49 (Ref.) & $112 / 181$ & Reference & $<0.001$ & Reference & 0.12 \\
\hline $50-54$ & $250 / 422$ & $0.90(0.63-1.28)$ & & $0.87(0.60-1.25)$ & \\
\hline $55-59$ & $512 / 803$ & $1.08(0.78-1.51)$ & & $0.98(0.70-1.38)$ & \\
\hline Female (Ref. male) & $4,627 / 6,390$ & $1.27(1.17-1.36)$ & $<0.001$ & $1.19(1.09-1.29)$ & $<0.001$ \\
\hline \multicolumn{6}{|l|}{ Household income (AUD/y) } \\
\hline$<20000$ (Ref.) & $2,823 / 3,799$ & Reference & $<0.001$ & Reference & $<0.001$ \\
\hline $20000-40000$ & $1,935 / 2,647$ & $0.94(0.84-1.05)$ & & $0.95(0.84-1.06)$ & \\
\hline $40000-70000$ & $1,048 / 1,599$ & $0.66(0.58-0.75)$ & & $0.72(0.63-0.83)$ & \\
\hline \multicolumn{6}{|l|}{ Highest education } \\
\hline Certificate/diploma/trade & $5,866 / 8,220$ & $0.95(0.85-1.06)$ & & $1.04(0.93-1.16)$ & \\
\hline University & $1,397 / 2,231$ & $0.64(0.56-0.72)$ & & $0.92(0.80-1.06)$ & \\
\hline
\end{tabular}

This article is protected by copyright. All rights reserved. 


\begin{tabular}{|c|c|c|c|c|c|}
\hline \multicolumn{6}{|l|}{ Quintile of SES } \\
\hline $1^{\text {st }}$ Quintile (Ref.) & $2,236 / 3,095$ & Reference & $<0.001$ & Reference & 0.005 \\
\hline $2^{\text {nd }}$ Quintile & $1,926 / 2,631$ & $1.05(0.93-1.18)$ & & $1.09(0.97-1.23)$ & \\
\hline $3^{\text {rd }}$ Quintile & $1,613 / 2,286$ & $0.92(0.82-1.04)$ & & $1.00(0.88-1.13)$ & \\
\hline $5^{\text {th }}$ Quintile & $1,705 / 2,635$ & $0.70(0.63-0.79)$ & & $0.88(0.77-1.00)$ & \\
\hline \multicolumn{6}{|l|}{ Remoteness } \\
\hline Outer Regional & $837 / 1,155$ & $1.23(1.07-1.42)$ & & $1.04(0.90-1.21)$ & \\
\hline Remote or very Remote & $49 / 83$ & $0.67(0.43-1.05)$ & & $0.59(0.37-0.92)$ & \\
\hline $\begin{array}{l}\text { English language speaking at home (Ref. other } \\
\text { languages) }\end{array}$ & $8,263 / 11,624$ & $1.69(1.50-1.90)$ & $<0.001$ & $1.65(1.46-1.87)$ & $<0.001$ \\
\hline \multicolumn{6}{|l|}{ Health insurance type } \\
\hline None of above & $935 / 1,356$ & $1.18(1.04-1.35)$ & & $1.01(0.88-1.16)$ & \\
\hline \multicolumn{6}{|l|}{ Clinical } \\
\hline \multicolumn{6}{|l|}{ BMI, $\mathrm{kg} / \mathrm{m}^{2}$} \\
\hline Underweight (Ref.) & $149 / 218$ & Reference & $<0.001$ & Reference & $<0.001$ \\
\hline
\end{tabular}

This article is protected by copyright. All rights reserved. 


\begin{tabular}{|c|c|c|c|c|c|}
\hline Normal & $3,250 / 4,488$ & $1.22(0.91-1.63)$ & & $1.28(0.95-1.73)$ & \\
\hline Overweight & $3,223 / 4,686$ & $1.02(0.76-1.37)$ & & $1.08(0.80-1.45)$ & \\
\hline Obesity & $1,704 / 2,523$ & $0.96(0.72-1.30)$ & & $0.99(0.73-1.34)$ & \\
\hline Diabetes (Ref. No) & $1,303 / 1,949$ & $0.85(0.76-0.94)$ & 0.001 & $0.83(0.74-0.93)$ & $<0.001$ \\
\hline High blood pressure (Ref. No) & $4,323 / 6,020$ & $1.18(1.10-1.28)$ & $<0.001$ & $1.18(1.09-1.27)$ & $<0.001$ \\
\hline \multicolumn{6}{|l|}{ Lifestyle } \\
\hline \multicolumn{6}{|l|}{ Smoker } \\
\hline Current smoker & $337 / 521$ & $0.78(0.64-0.93)$ & & $0.77(0.63-0.93)$ & \\
\hline Alcohol consumption per week & $1,577 / 2,284$ & $0.95(0.86-1.05)$ & 0.28 & $1.04(0.93-1.15)$ & 0.69 \\
\hline \multicolumn{6}{|l|}{ ( $\geq 14$ drinks) (Ref. $<14$ drinks) } \\
\hline \multicolumn{6}{|l|}{ PA (session/week) } \\
\hline$<5$ (Ref.) & $1,953 / 2,812$ & Reference & 0.33 & Reference & 0.20 \\
\hline$\geq 300 \min$ (Ref.) & $3,803 / 5,442$ & Reference & 0.08 & Reference & 0.26 \\
\hline $150-300 \mathrm{~min}$ & $1,061 / 1,565$ & $0.91(0.80-1.02)$ & & $0.94(0.83-1.07)$ & \\
\hline$\leq 150 \min$ & $3,572 / 5,050$ & $1.04(0.96-1.13)$ & & $1.02(0.93-1.13)$ & \\
\hline $\begin{array}{l}\text { Medication-related factors } \\
\text { (Last visit) }\end{array}$ & & & & & \\
\hline
\end{tabular}

This article is protected by copyright. All rights reserved. 


\begin{tabular}{lcccc}
\hline No. of medications & & & & \\
$\quad 1$ (Ref.) & $8,334 / 12,059$ & Reference & $<0.001$ & Reference \\
2 & $616 / 759$ & $1.93(1.60-2.32)$ & $2.08(1.71-2.53)$ & $3.23(1.71-6.09)$ \\
$\geq 3$ & $69 / 81$ & $2.57(1.39-4.75)$ & 0.001 & $1.02(0.92-1.14)$ \\
Use of FDC (Ref. No) & $1,789 / 2,490$ & $1.12(1.02-1.23)$ & 0.02 & 0.69 \\
Use of beta-blocker (Ref. No) & $1,427 / 2,109$ & $0.88(0.80-0.97)$ & 0.01 & $0.74(0.66-0.81)$ \\
Use of adrenergic (Ref. No) & $634 / 905$ & $1.01(0.87-1.16)$ & 0.93 & $0.80(0.68-0.93)$ \\
Use of cholinergic (Ref. No) & $87 / 138$ & $0.73(0.52-1.03)$ & 0.08 & $0.55(0.38-0.79)$ \\
Use of CAI (Ref. No) & $441 / 575$ & $1.43(1.18-1.75)$ & $<0.001$ & $1.11(0.91-1.37)$ \\
Use of prostaglandin analogues (Ref. No) & $5,398 / 7,606$ & $1.12(1.04-1.22)$ & 0.02 & $0.96(0.87-1.05)$ \\
\hline
\end{tabular}

Abbreviation: OR = odds ratio; $\mathrm{CI}=$ confidence interval; SES = social economic status; PA = physical activity; MVPA = moderate to vigorous physical activity; FDC = fixed combination; CAI = carbonic anhydrase inhibitor;

${ }^{\dagger}$ Adjusted for all factors in unadjusted models. 


\begin{tabular}{|c|c|}
\hline $\begin{array}{l}\text { All participants } \\
\mathrm{N}=266,896\end{array}$ & \\
\hline & $\begin{array}{l}\mathrm{N}=247,593 \text { with less than } 3 \text { claims with } \\
\text { glaucoma drug prescriptions }\end{array}$ \\
\hline \multirow{2}{*}{$\begin{array}{l}\text { Patients in need of persistent } \\
\text { glaucoma medication treatment } \\
\qquad(\mathrm{N}=19,303) \\
\text { Definition: } \geq 3 \text { claims with } \\
\text { glaucoma drug claims }\end{array}$} & \\
\hline & Excluded: \\
\hline & study period (2006-2016) \\
\hline $\begin{array}{l}\text { Eligible participants } \\
\qquad(\mathrm{N}=12,899)\end{array}$ & $\begin{array}{l}N=1,522 \text { reaching study end date within } \\
2 \text { years after the index day* }\end{array}$ \\
\hline
\end{tabular}

CEO_13524_figure_1.tiff 


\section{University Library}

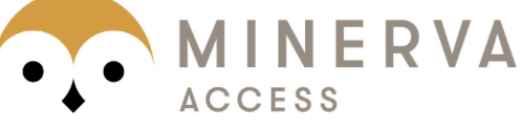

A gateway to Melbourne's research publications

Minerva Access is the Institutional Repository of The University of Melbourne

Author/s:

Zhu, Z;Jiang, Y;Wang, W;Scheetz, J;Shang, X;Zhang, L;He, M

Title:

Real-world assessment of topical glaucoma medication persistence rates based on national pharmaceutical claim data in a defined population

Date:

2019-09-01

\section{Citation:}

Zhu, Z., Jiang, Y., Wang, W., Scheetz, J., Shang, X., Zhang, L. \& He, M. (2019). Realworld assessment of topical glaucoma medication persistence rates based on national pharmaceutical claim data in a defined population. CLINICAL AND EXPERIMENTAL OPHTHALMOLOGY, 47 (7), pp.881-891. https://doi.org/10.1111/ceo.13524.

Persistent Link:

http://hdl.handle.net/11343/285867 